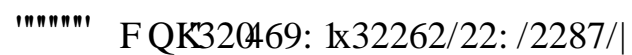

\section{RISKS TO CARRIAGE SAFETY RELATING TO HUMP TRACK ARRANGEMENT}

\section{ZAGROŻENIE BEZPIECZEŃSTWA WAGONÓW KSZTALTEM UKLADU TORÓW GÓRKI ROZRZĄDOWEJ}

\author{
Cieślakowski Stanisław J. \\ Technical University of Radom, Faculty of Transport \\ ul. Malczewskego 29, 26-600 Radom, Polska \\ Politechnika Radomska, Wydzial Transportu \\ ul. Malczewskego 29, 26-600 Radom, Polska \\ e-mail: ist@pr.radom.pl
}

\begin{abstract}
A method of computing the likelihood of risk to carriage safety at destination and distance brakes as resulting from arrangements of hump tracks.
\end{abstract}

Keywords: safety, hump tracks

Streszczenie: W pracy opracowano metodę obliczania prawdopodobieństwa zagrożenia bezpieczeństwa wagonów na hamulcach docelowych i odstępowych przez kształt układu torów górki rozrządowej.

Słowa kluczowe: bezpieczeństwo, górka rozrządowa 


\section{RISKS TO CARRIAGE SAFETY RELATING TO HUMP TRACK ARRANGEMENT}

\section{Introduction}

Considerable maneuvering effort focuses at railroad centers at intersections of major transit routes and in the vicinity of industrial centers where much loading is concentrated. Carriages arriving at such locations must be distributed according to their travel direction and destination, and then trained together. These operations are executed at marshalling, maneuvering, and industrial yards.

Marshalling and train setting constitute most of the maneuvering at these yards.

Large marshalling, maneuvering, and industrial yards are equipped with gravitational marshalling systems which enable most effective wagon marshalling.

During a single trip, each carriage is marshaled at least 3 times by means of gravitational marshalling systems:

- on loading at the loading area marshalling yard,

- prior to unloading at the unloading area marshalling yard,

- as an empty wagon on unloading at the unloading area marshalling yard.

Carriage safety is most at risk when marshaled in gravitational marshalling systems, inter alias, at destination and distance brakes.

Computation of this risk is very difficult.

\section{Current knowledge of the issue}

Global research into wagon safety in gravitational marshalling systems goes back to 1950s [7].

B. Gajda [5] computes maximum speeds of carriage pushing onto hump top with respect to efficiency of gravitational marshalling systems. These calculations involve one track system and use classic analytical method.

J. Węgierski [8] cites results of some research conducted on German, Russian, and Swiss railroads. 
Damage to goods carriages in the marshalling process is analysed in [6]. Field measurements and mathematical statistics are employed in this research.

The issue of wagon safety in gravitational marshalling systems is analysed in [4], where simulation models, developed at the Faculty of Transport, Technical University of Warsaw, are used.

None of these references, or [1], concerning the issue present any methods of calculating risk to carriage safety.

\section{Problem formulation}

Only qualitative assessments of wagon safety in gravitational marshalling systems are undertaken at present. Among other endeavors, it is verified if wagon speeds at destination and distance brakes are not too great.

When designing or modernizing gravitational marshalling systems, it cannot be established which of them are better in regard of carriage safety and to what extent.

A function $\mathrm{F}$ needs to be developed, converting an arrangement of hump tracks $\mathrm{K}$ into risk to carriage safety at destination and distance brakes of the system, $\mathrm{Z}_{\mathrm{HD}}$ and $\mathrm{Z}_{\mathrm{HO}}$ :

$$
\mathrm{F}: \mathrm{K} \rightarrow\left(\mathrm{Z}_{\mathrm{HD}}, \mathrm{Z}_{\mathrm{HO}}\right)
$$

\section{Method and results}

\subsection{Risk to carriage safety resulting from track arrangement at destination brakes}

Outline plans of division zones and the marshalling process are analyzed, and analytical calculations simulating wagon rolling are employed.

As there are no numerical criteria of safety assessment, shortcomings cannot be fully disclosed and measures cannot be defined to improve safety standards.

Probabilistic methods of safety appraisal tend to be employed more and more often.

Risk is the opposite of safety.

Velocity of wagons arriving at a destination brake $\mathrm{V}_{\mathrm{HD}}$ can be determined by means of a composite function [2]:

$$
\mathrm{V}_{\mathrm{HD}}=\mathrm{f}\left(\mathrm{K}_{\mathrm{c}}, \mathrm{PW}_{\mathrm{c}}\right)
$$

$\mathrm{K}_{\mathrm{c}}$ - hump track arrangement from top to destination brake, 
$\mathrm{PW}_{\mathrm{c}}-$ selected parameters of a heavy goods wagon.

A type (2) can be expressed by means of Maclaurin's formula:

$$
\mathrm{V}_{\mathrm{HD}}=4,24 \sqrt{\mathrm{H}_{\mathrm{c}}-0,0016 \cdot \mathrm{L}_{\mathrm{c}}-\mathrm{c}_{\mathrm{c}}}-\frac{2,12 \cdot \mathrm{L}_{\mathrm{c}}}{\sqrt{\mathrm{H}_{\mathrm{c}}-0,0016 \cdot \mathrm{L}_{\mathrm{c}}-\mathrm{c}_{\mathrm{c}}}} \cdot \mathrm{w}_{0}+\mathrm{R}_{\mathrm{c}}[\mathrm{m} / \mathrm{s}]
$$

where:

$\mathrm{L}_{\mathrm{c}}$ - distance from hump top to the start of destination brakes [m],

$\mathrm{H}_{\mathrm{c}}$ - height from hump top to the start of destination brakes [m],

$\mathrm{c}_{\mathrm{c}}-$ constant that equals 0.41 and 0.48 for carriage pushing velocity of $1.4 \mathrm{~m} / \mathrm{s}$ and $0.8 \mathrm{~m} / \mathrm{s}$, respectively,

$\mathrm{W}_{\mathrm{o}}-$ unit rolling resistance of carriages,

$\mathrm{R}_{\mathrm{c}}$ - remainder of circa 0.13 , negligible for purposes of the present approximation.

A type (3) bases on the following assumptions:

a) wagon 2 - axial, empty - is considered,

b) the wagon is not restrained by the distance brake,

c) the wagon's travel to a directional track of least resistance is considered, as the risk of wagon derailment is greatest at the destination brake located there,

d) unit rolling resistance of $\mathrm{j}^{\text {th }}$ carriage is assumed as a random variable of normal distribution.

A postulate $d$ ) implies that the speed of $\mathrm{j}^{\text {th }}$ carriage at the destination brake is a random variable as well.

Employing the probability density function of the wagon arriving at the destination brake and the table of normal distribution function, the probability of risk to carriage safety arising from velocity at destination brakes can be computed.

A carriage is derailed when the velocity of its arrival at the brakes is greater than $\mathrm{V}_{\mathrm{HD}}=5.5 \mathrm{~m} / \mathrm{s}$, which can be formulated:

where:

$$
\mathrm{Z}_{\mathrm{HD}}=\mathrm{p}_{\mathrm{WYD}}=\mathrm{p}\left(\mathrm{V}_{\mathrm{HD}}>5,5\right)
$$

$\mathrm{p}_{\mathrm{WYD}}$ - the probability of risk to carriage safety arising from velocity at destination brakes (probability of wagon derailment).

The calculations assumed $\mathrm{L}=396.5 \mathrm{~m}, \mathrm{H}=4.78 \mathrm{~m}$.

\subsection{Risk to carriage safety resulting from track arrangement at distance brakes}


Velocity of carriage entering a distance brake $\mathrm{V}_{\mathrm{HO}}$ can be determined by means of a function of several variables [2]:

$$
\mathrm{V}_{\mathrm{HO}}=\mathrm{f}\left(\mathrm{K}_{1}, \mathrm{PW}_{\mathrm{l}}\right)
$$

$\mathrm{K}_{1}$ - hump track arrangement from top to distance brake, $\mathrm{PW}_{1}$ - selected parameters of a light goods wagon.

A function (5) can be expressed by means of Maclaurin's formula:

$$
\mathrm{V}_{\mathrm{HO}}=4,37 \sqrt{\mathrm{H}_{1}-\mathrm{c}_{1}}-\frac{2.19 \cdot \mathrm{L}}{\sqrt{\mathrm{H}_{1}-\mathrm{c}_{1}}} \cdot \mathrm{w}_{\mathrm{o}}+\mathrm{R}_{1} \quad[\mathrm{~m} / \mathrm{s}]
$$

where:

$\mathrm{L}_{1}-$ distance from hump top to the start of distance brakes [m],

$\mathrm{H}_{1}$ - height from hump top to the start of distance brakes [m],

$\mathrm{c}_{1}$ - constant that equals 0.04 and 0.11 for carriage pushing velocity of $1.4 \mathrm{~m} / \mathrm{s}$ and $0.8 \mathrm{~m} / \mathrm{s}$,

$\mathrm{W}_{\mathrm{o}}-$ unit rolling resistance of carriage,

$\mathrm{R}_{1}$ - remainder $\mathrm{R}=0$ for purposes of the present approximation.

A type (6) rests on the following assumptions:

a) air resistance is negligible in the case of light carriage (approx. 10 times lower than the unit rolling resistance),

b) modified acceleration of gravity g $=9.57 \mathrm{~m} / \mathrm{s}$ like in regard of new light carriages $\mathrm{E}_{\mathrm{anos}}-423 \mathrm{~W}$,

c) the carriage passes through $n=3$ turnouts between the top and the distance brake,

d) factor of sum total of turning angles is 0.008 ,

e) sum total of turning angles is $\alpha=10^{\circ}$.

It can be assumed, somewhat simplifying, that unit rolling resistance of $\mathrm{j}^{\text {th }}$ carriage is a random variable of normal distribution:

$$
\mathrm{N}\left(\overline{\mathrm{w}}_{\mathrm{o}}, \sigma_{\mathrm{ow}}\right) \text {, }
$$

where:

$$
\begin{aligned}
& \overline{\mathrm{w}}_{\mathrm{o}}=0,00311 \\
& \sigma_{\mathrm{wo}}=0,00101
\end{aligned}
$$

Therefore, the speed of $\mathrm{j}^{\text {th }}$ carriage at the distance brake is a random variable as well. Substituting $\mathrm{w}_{\mathrm{o}}=\overline{\mathrm{w}}_{\mathrm{o}}$ in (6), the formula produces the expected value of $\overline{\mathrm{V}}_{\mathrm{HO}}$.

Standard deviation of velocity relates to the dependence: 


$$
\sigma_{\mathrm{V}_{\text {но }}}^{2}=\left(\frac{2,19 \cdot \mathrm{L}_{1}}{\sqrt{\mathrm{H}_{1}-\mathrm{c}_{1}}}\right)^{2} \sigma_{\text {wo }}^{2}
$$

Employing the probability density function of the wagon arriving at the distance brake and the table of normal distribution function, the probability of risk to carriage safety at distance brakes, or the probability of carriage derailment $p_{w y o}$, can be computed.

$$
\mathrm{Z}_{\mathrm{HO}}=\mathrm{p}_{\mathrm{WYO}}=\mathrm{p}\left(\mathrm{V}_{\mathrm{HO}}>8,5\right)
$$

A carriage is derailed when the velocity of its arrival at the brakes is greater than $\mathrm{V}_{\mathrm{HD}}=8.5 \mathrm{~m} / \mathrm{s}$.

Calculations assumed $\mathrm{L}=138 \mathrm{~m}$ and $\mathrm{H}=3.92 \mathrm{~m}$. These dimensions correspond to a 32-track system with one ridge track.

Assuming a series arrangement of factors affecting a carriage, the risk to wagon safety arising from arrangement of hump tracks can be formulated:

$$
\mathrm{Z}=1-\left(1-\mathrm{p}_{\mathrm{WYD}}\right)\left(1-\mathrm{p}_{\mathrm{WYO}}\right)
$$

\section{Conclusion}

This research leads to the following conclusions:

1. Numerical evaluation of risk to carriage safety at destination brakes according to the present method is carried out with respect to two destination brakes. This is related to the symmetry of track system.

2. Real probability of risk to this safety can be obtained by multiplying the probability computed in (4) by the probability of a 2-axle carriage and empty carriage appearing in the gravitational marhalling system, and the likelihood of a wagon traveling along a track of least resistance.

3. Therefore, the real probability of carriages derailing at destination brakes, with pushing velocities of $1.4 \mathrm{~m} / \mathrm{s}$ and $0.8 \mathrm{~m} / \mathrm{s}$, is approximately 0.0009 .

4. Quantitative assessment of risk to carriage safety at destination brakes according to the present method in consideration of one brake is sufficient. This approach is valid in view of the symmetry of the track arrangement.

5. Risk to carriage safety in the gravitational marshalling system, i.e. the probability of its derailment at destination brakes, with pushing velocities of $1.4 \mathrm{~m} / \mathrm{s}$ and $0.8 \mathrm{~m} / \mathrm{s}$, is 0.0107 and 0.00005 , respectively.

6 . Real probability of risk to carriage safety relating to velocity at distance brakes can be obtained by multiplying the computed probability by the 
likelihood of a four-axle wagon appearing in the gravitational marshalling system and by the probability that the same wagon is loaded.

7. Total risk to carriage safety as relating to the arrangement of hump tracks and computed in (9) is 0.009 and 0.0009 at the wagon marshalling speed of $1.4 \mathrm{~m} / \mathrm{s}$ and $0.8 \mathrm{~m} / \mathrm{s}$, respectively.

\section{References}

[1] Buława M.: Minimalizacja zjawiska doganiania się odprzęów w metodzie prowadzenia do celu. (Minimisation of Catching-Up of Carriage Sets in Destination-Driving Method) Scientific Publications of the Technical University of Radom, Transport 2(20), Radom 2004.

[2] Cieślakowski St. J.: Stacje kolejowe (Railway Stations). WKŁ, Warsaw 1992.

[3] Cieślakowski St.J.: Kształtowanie bezpieczeństwa wagonów w systemach rozrządzania grawitacyjnego (Managing Safety of Rail carriages in Gravitational Mars halling Systems). Research paper 2005/47/P. Technical University of Radom, Radom 2004.

[4] Ciszewski B., Kozak T.: Wpływ stopnia wyposażenia technicznego i technologii procesu rozrządzania wagonów na wydajność etapowo automatyzowanych górek rozrządowych PKP (Effect of Technical Equipment and Carriage Marshalling Process on Efficiency of Polish National Railways PKP Humps Being Automated In Stages). COBi RTK, Warsaw 1989.

[5] Gajda B.: Technologia i automatyzacja pracy stacji (Technology and Automattion of Station Operations). WPW, Warsaw 1983.

[6] Janiak M., Tomaszczyk T., Koralewski E.: Analiza uszkodzeń wagonów towarowych powstałych w procesie rozrządzania (Analysis of Damage to Goods Carriages Arising in the Marshalling Process). COBi RTK, Warsaw 1978.

[7] Müller W.: Eisenbahnwesen. Springer - Verlag. Berlin Zach. 1955.

[8] Węgierski J.: Układy torowe stacji (Station Track Arrangements). WKŁ, Warsaw 1974. 


\section{ZAGROŻENIE BEZPIECZEŃSTWA WAGONÓW KSZTALTEM UKLADU TORÓW GÓRKI ROZRZĄDOWEJ}

\section{Wstęp}

W węzłach kolejowych na przecięciu zasadniczych ciaggów tranzytowych oraz w pobliżu ośrodków przemysłowych o znacznej pracy ładunkowej, zachodzi potrzeba wykonywania znacznej pracy manewrowej. Wagony przybywające do tych miejsc trzeba podzielić według kierunków odjazdu oraz stacji docelowych przewozu, a następnie zestawić je w pociagi. Czynności te wykonuje się na stacjach rozrządowych, manewrowych i zakładowych.

Podstawowy zakres pracy manewrowej na tych stacjach stanowi rozrządzanie i zestawianie składów pociagów towarowych.

Duże stacje rozrządowe, manewrowe i zakładowe są wyposażone w systemy rozrządzania grawitacyjnego umożliwiające najbardziej wydajne rozrządzanie wagonów. Każdy wagon towarowy w czasie swojego tylko jednego obrotu jest przynajmniej 3 razy rozrządzany $\mathrm{z}$ wykorzystaniem systemów rozrządzania grawitacyjnego:

- po załadunku na stacji rozrządowej rejonu załadunku,

- przed wyładunkiem na stacji rozrządowej rejonu wyładunku,

- jako wagon próżny po wyładunku na stacji rozrządowej rejonu wyładunku.

Największe zagrożenie bezpieczeństwa wagonów na stacji występuje podczas ich rozrządzania $\mathrm{w}$ systemach rozrządzania grawitacyjnego, m.in. na hamulcach docelowych i odstępowych.

Duże trudności sprawia liczbowe wyznaczenie tego zagrożenia.

\section{Aktualny stan wiedzy o zagadnieniu}

Zagadnieniem bezpieczeństwa wagonów w systemach rozrządzania grawitacyjnego zajmowano się $\mathrm{w}$ świecie już $\mathrm{w}$ latach pięćdziesiątych ubiegłego wieku [7].

B. Gajda w pracy [5] oblicza maksymalne prędkości napychania wagonów na wierzchołek górki rozrządowej $\mathrm{W}$ aspekcie wydajności systemu rozrządzania grawitacyjnego. Obliczenia przeprowadza dla jednego układu torowego, stosując do tego celu klasyczną metodę analityczną. 
J. Węgierski w pracy [8] przytacza niektóre wyniki badań przeprowadzonych na kolejach niemieckich, rosyjskich i szwajcarskich.

Analizą uszkodzeń wagonów towarowych w procesie rozrządzania zajmowano się w pracy [6]. Jako metody badawcze zastosowano pomiary w terenie i statystykę matematyczną.

Problem bezpieczeństwa wagonów w systemach rozrządzania grawitacyjnego analizowany jest w pracy [4], gdzie wykorzystano modele symulacyjne opracowane na Wydziale Transportu Politechniki Warszawskiej.

Żadna $\mathrm{z}$ powyższych prac oraz inne [1] dotyczące tego zagadnienia nie przedstawiają metody obliczenia zagrożenia bezpieczeństwa wagonów.

\section{Sformulowanie problemu}

Obecnie dokonuje się tylko jakościowej oceny bezpieczeństwa wagonów w systemach rozrządzania grawitacyjnego.

Polega to m.in. na tym, że sprawdza się czy wagony nie mają zbyt dużych prędkości na hamulcach docelowych i odstępowych.

Projektując nowe systemy rozrządzania grawitacyjnego lub modernizując już istniejące, nie możemy stwierdzić, które z nich są lepsze i o ile dla bezpieczeństwa wagonów.

Należy więc opracować funkcję $\mathrm{F}$ transformującą kształt układu torów górki rozrządowej $\mathrm{K}$ na zagrożenie bezpieczeństwa wagonów kolejowych na hamulcach docelowych i odstępowych tego systemu $\mathrm{Z}_{\mathrm{HD}} \mathrm{i} \mathrm{Z}_{\mathrm{HO}}$ :

$$
\mathrm{F}: \mathrm{K} \rightarrow\left(\mathrm{Z}_{\mathrm{HD}}, \mathrm{Z}_{\mathrm{HO}}\right)
$$

\section{Metoda badań i wyniki}

\subsection{Zagrożenie bezpieczeństwa wagonów kształtem układu torów na hamulcach docelowych}

Jako metodę badawczą zastosowano analizę planów schematycznych stref podziałowych oraz procesu technologicznego rozrządzania i obliczenia analityczne symulujące staczanie wagonów.

Brak kryteriów liczbowej oceny bezpieczeństwa nie pozwala $\mathrm{w}$ pełnej mierze ujawnić niedociagnięć i podjąć przedsięwzięcia, które zwiększyłyby poziom bezpieczeństwa.

Pojawiła się obecnie tendencja do szerokiego wykorzystania probabilistycznych metod oceny bezpieczeństwa.

Przeciwieństwem bezpieczeństwa jest zagrożenie.

Prędkość wjazdu wagonów na hamulec docelowy $\mathrm{V}_{\mathrm{HD}}$ można wyznaczyć za pomocą funkcji złożonej [2]: 


$$
\mathrm{V}_{\mathrm{HD}}=\mathrm{f}\left(\mathrm{K}_{\mathrm{c}}, \mathrm{PW}_{\mathrm{c}}\right)
$$

$\mathrm{K}_{\mathrm{c}}-$ kształt układu torów górki rozrządowej od wierzchołka do hamulca docelowego,

$\mathrm{PW}_{\mathrm{c}}$ - wybrane parametry wagonu ciężkobieżnego.

Funkcję (2) można przedstawić za pomocą wzoru Maclaurina w następujący sposób:

$$
\mathrm{V}_{\mathrm{HD}}=4,24 \sqrt{\mathrm{H}_{\mathrm{c}}-0,0016 \cdot \mathrm{L}_{\mathrm{c}}-\mathrm{c}_{\mathrm{c}}}-\frac{2,12 \cdot \mathrm{L}_{\mathrm{c}}}{\sqrt{\mathrm{H}_{\mathrm{c}}-0,0016 \cdot \mathrm{L}_{\mathrm{c}}-\mathrm{c}_{\mathrm{c}}}} \cdot \mathrm{w}_{0}+\mathrm{R}_{\mathrm{c}}[\mathrm{m} / \mathrm{s}]
$$

gdzie:

$\mathrm{L}_{\mathrm{c}}$ - odległość od wierzchołka górki rozrządowej do początku hamulców docelowych $[\mathrm{m}]$,

$\mathrm{H}_{\mathrm{c}}$ - wysokość między wierzchołkiem górki a początkiem hamulców docelowych $[\mathrm{m}]$,

$\mathrm{c}_{\mathrm{c}}$ - stała wynosząca dla prędkości napychania wagonów $1,4 \mathrm{~m} / \mathrm{s}$ oraz 0.8 $\mathrm{m} / \mathrm{s}$ odpowiednio 0,41 i 0,48 ,

$\mathrm{w}_{\mathrm{o}}$ - jednostkowy opór toczenia wagonu,

$\mathrm{R}_{\mathrm{c}}$ - reszta, którą dla wykonanej aproksymacji można pominąć, gdyż jej wartość kształtuje się na poziomie 0,13.

Postać wzoru (3) została opracowana przy następujących założeniach:

a) rozpatrywano wagon 2 - osiowy, próżny,

b) wagon ten nie podlega hamowaniu na hamulcu odstępowym,

c) rozpatrywano ruch tego wagonu na tor kierunkowy o najmniejszym oporze, gdyż na hamulcu docelowym tu zlokalizowanym, występuje największe zagrożenie wykolejenia wagonu,

d)przyjęto, że jednostkowy opór toczenia dowolnego j-tego wagonu jest zmienną losową o rozkładzie normalnym.

$\mathrm{Z}$ założenia d) wynika, że prędkość j-tego wagonu na hamulcu docelowym jest również zmienną losową.

Korzystając z funkcji gęstości rozkładu prawdopodobieństwa prędkości wjazdu wagonu na ten hamulec docelowy oraz tablicy dystrybuanty rozkładu normalnego, można obliczyć prawdopodobieństwo zagrożenia bezpieczeństwa wagonów elementem prędkości na hamulcach docelowych.

Wykolejenie następuje, gdy prędkość wjazdu wagonów na hamulce przekracza $\mathrm{V}_{\mathrm{HD}}=5,5 \mathrm{~m} / \mathrm{s}$, co możemy zapisać:

$$
\mathrm{Z}_{\mathrm{HD}}=\mathrm{p}_{\mathrm{WYD}}=\mathrm{p}\left(\mathrm{V}_{\mathrm{HD}}>5,5\right)
$$


gdzie:

$\mathrm{p}_{\mathrm{WYD}}$ - prawdopodobieństwo zagrożenia bezpieczeństwa wagonów elementem prędkości na hamulcach docelowych (prawdopodobieństwo wykolejenia wagonów).

Obliczenia przeprowadzono dla $\mathrm{L}=396,5 \mathrm{~m}, \mathrm{H}=4,78 \mathrm{~m}$.

4.2. Zagrożenia bezpieczeństwa wagonów kształtem układu torów na hamulcach odstepowych

Prędkość wjazdu wagonów na hamulec odstępowy $\mathrm{V}_{\text {HO }}$ można wyznaczyć za pomocą funkcji wielu zmiennych [2]:

$$
\mathrm{V}_{\mathrm{HO}}=\mathrm{f}\left(\mathrm{K}_{1}, \mathrm{PW}_{\mathrm{l}}\right)
$$

$\mathrm{K}_{1}$ - kształt układu torów górki rozrządowej od wierzchołka do hamulca odstępowego,

$\mathrm{PW}_{1}$ - wybrane parametry wagonu lekkobieżnego.

Funkcję (5) można przedstawić za pomocą wzoru Maclaurina W następujący sposób:

$$
\mathrm{V}_{\mathrm{HO}}=4,37 \sqrt{\mathrm{H}_{1}-\mathrm{c}_{1}}-\frac{2.19 \cdot \mathrm{L}}{\sqrt{\mathrm{H}_{1}-\mathrm{c}_{1}}} \cdot \mathrm{w}_{\mathrm{o}}+\mathrm{R}_{1} \quad[\mathrm{~m} / \mathrm{s}]
$$

gdzie:

$\mathrm{L}_{1}$ - odległość od wierzchołka górki rozrządowej do początku hamulców odstępowych [m],

$\mathrm{H}_{1}$ - wysokość między wierzchołkiem górki a początkiem hamulców odstępowych $[\mathrm{m}]$,

$\mathrm{c}_{1}$ - stała wynosząca dla prędkości napychania wagonów $1,4 \mathrm{~m} / \mathrm{s}$ oraz $0,8 \mathrm{~m} / \mathrm{s}$ odpowiednio 0,04 i 0,11 ,

$\mathrm{w}_{\mathrm{o}}$ - jednostkowy opór toczenia wagonu,

$\mathrm{R}_{1}$ - reszta, która dla wykonanej aproksymacji wynosi $\mathrm{R}=0$.

Postać wzoru (6) została opracowana przy następujących założeniach:

a) opór od powietrza został pominięty ze względu na jego znikomą wartość oddziaływania na wagon lekkobieżny (około 10 razy mniejszy od jednostkowego oporu toczenia wagonu),

b) zmodyfikowane przyspieszenia ziemskie $\mathrm{g}=9,57 \mathrm{~m} / \mathrm{s}$ jak dla nowych wagonów lekkobieżnych $\mathrm{E}_{\text {anos }}-423 \mathrm{~W}$,

c) liczba rozjazdów przejeżdżanych przez wagon między wierzchołkiem a hamulcem odstępowym wynosi $n=3$,

d) współczynnik przy sumie kątów zwrotu wynosi 0,008 ,

e) suma kątów zwrotu wynosi $\alpha=10^{\circ}$. 
Można przyjąć, z pewnym uproszczeniem, że jednostkowy opór toczenia dowolnego j-tego wagonu jest zmienną losową o rozkładzie normalnym:

$$
\mathrm{N}\left(\overline{\mathrm{w}}_{\mathrm{o}}, \sigma_{\mathrm{ow}}\right),
$$

gdzie:

$$
\begin{aligned}
& \overline{\mathrm{w}}_{\mathrm{o}}=0,00311 \\
& \sigma_{\mathrm{wo}}=0,00101
\end{aligned}
$$

Wobec tego prędkość j-tego wagonu na hamulcu odstępowym jest również zmienną losowa.

Wstawiając do wzoru (6) $\mathrm{w}_{\mathrm{o}}=\overline{\mathrm{w}}_{\mathrm{o}}$, otrzymujemy wzór na wartość oczekiwaną prędkości $\overline{\mathrm{V}}_{\mathrm{HO}}$.

Odchylenie standardowe prędkości związane jest zależnością:

$$
\sigma_{\mathrm{v}_{\text {но }}}^{2}=\left(\frac{2,19 \cdot \mathrm{L}_{1}}{\sqrt{\mathrm{H}_{1}-\mathrm{c}_{1}}}\right)^{2} \sigma_{\text {шо }}^{2}
$$

Korzystając z funkcji gęstości rozkładu prawdopodobieństwa prędkości wjazdu j-tego wagonu na hamulec odstępowy oraz tablicy dystrybuanty rozkładu normalnego, można obliczyć zagrożenie bezpieczeństwa wagonów na hamulcach odstępowych, czyli prawdopodobieństwo wykolejenia wagonów na tych hamulcach $\mathrm{p}_{\mathrm{wy}}$.

$$
\mathrm{Z}_{\mathrm{HO}}=\mathrm{p}_{\mathrm{WYO}}=\mathrm{p}\left(\mathrm{V}_{\mathrm{HO}}>8,5\right)
$$

Wykolejenie następuje gdy prędkość wjazdu wagonów na hamulce odstępowe przekracza $\mathrm{V}_{\mathrm{HO}}=8,5 \mathrm{~m} / \mathrm{s}$.

Obliczenia te przeprowadzono dla $\mathrm{L}=138 \mathrm{~m} \mathrm{i} \mathrm{H}=3,92 \mathrm{~m}$. Wymiary te odpowiadają 32-torowemu układowi z jednym torem grzbietowym.

Przyjmując system o szeregowym układzie oddziałujących na wagon czynników, można napisać wzór na zagrożenie bezpieczeństwa wagonów kształtem układu torów górki rozrządowej:

$$
\mathrm{Z}=1-\left(1-\mathrm{p}_{\mathrm{WYD}}\right)\left(1-\mathrm{p}_{\mathrm{WYo}}\right)
$$




\section{Wnioski}

Z badań wykonanych w pracy wynikają następujące wnioski:

1. Liczbowej oceny zagrożenia bezpieczeństwa wagonów na hamulcach docelowych według opracowanej metody dokonuje się dla dwóch hamulców docelowych. Wynika to z symetrii układu torowego.

2. Rzeczywiste prawdopodobieństwo zagrożenia powyższego bezpieczeństwa otrzymamy mnożąc obliczone ze wzoru (4) prawdopodobieństwo przez prawdopodobieństwa pojawienia się w systemie rozrządzania grawitacyjnego wagonu 2-osiowego, wagonu próżnego oraz jazdy wagonu na tor o najmniejszym oporze.

3. Tak więc rzeczywiste prawdopodobieństwo wykolejenia wagonów na hamulcach docelowych dla prędkości napychania $1,4 \mathrm{~m} / \mathrm{s}$ oraz $0,8 \mathrm{~m} / \mathrm{s}$ kształtuje się na poziomie 0,0009 .

4. Ilościowej oceny zagrożenia bezpieczeństwa wagonów na hamulcach odstępowych według opracowanej metody wystarczy dokonać dla jednego hamulca. Podejście takie jest uprawnione ze względu na symetrię układu torowego.

5. Zagrożenie bezpieczeństwa wagonów w systemie rozrządzania grawitacyjnego, czyli prawdopodobieństwo ich wykolejenia na hamulcach odstępowych dla prędkości napychania wynoszących $1,4 \mathrm{~m} / \mathrm{s}$ oraz 0,8 $\mathrm{m} / \mathrm{s}$ wynosi odpowiednio 0,0107 oraz 0,00005 .

6. Rzeczywiste prawdopodobieństwo zagrożenia bezpieczeństwa wagonów elementem prędkości na hamulcach odstępowych otrzymamy, mnożąc obliczone prawdopodobieństwo przez prawdopodobieństwo pojawienia się wagonu czteroosiowego w systemie rozrządzania grawitacyjnego i prawdopodobieństwo, że jest on ładowny.

7. Całkowite zagrożenie bezpieczeństwa wagonów kształtem układu torów górki rozrządowej obliczone ze wzoru (9) wynosi przy prędkości rozrządzania wagonów $1,4 \mathrm{~m} / \mathrm{s}$ oraz $0,8 \mathrm{~m} / \mathrm{s}$ odpowiednio 0,009 oraz 0,0009 . 
